\title{
Evaluation of Biological Activities of Chemically Synthesized Silver Nanoparticles
}

\author{
Ashraf A. Mostafa, ${ }^{1}$ Shaban R. M. Sayed, ${ }^{2}$ Essam N. Solkamy, ${ }^{1}$ Mujeeb Khan, ${ }^{3}$ \\ Mohammed Rafi Shaik, ${ }^{3}$ Abdulrahman Al-Warthan, ${ }^{3}$ and Syed Farooq Adil ${ }^{3}$ \\ ${ }^{1}$ Botany and Microbiology Department, College of Science, King Saud University, P.O. Box 2455, Riyadh 11451, Saudi Arabia
${ }^{2}$ Electron Microscope Unit, Central Laboratory, College of Science, King Saud University, P.O. Box 2455, Riyadh 11451, Saudi Arabia
${ }^{3}$ Chemistry Department, College of Science, King Saud University, P.O. Box 2455, Riyadh 11451, Saudi Arabia \\ Correspondence should be addressed to Syed Farooq Adil; sfadil@ksu.edu.sa
}

Received 8 September 2015; Revised 10 November 2015; Accepted 25 November 2015

Academic Editor: Lavinia Balan

Copyright (C) 2015 Ashraf A. Mostafa et al. This is an open access article distributed under the Creative Commons Attribution License, which permits unrestricted use, distribution, and reproduction in any medium, provided the original work is properly cited.

Silver nanoparticles were synthesized by the earlier reported methods. The synthesized nanoparticles were characterized using ultraviolet-visible spectrophotometry (UV/Vis), transmission electron microscopy (TEM), energy dispersive X-ray spectroscopy (EDX), and X-ray powder diffraction (XRD). The synthesized materials were also evaluated for their antibacterial activity against Gram positive and Gram negative bacterial strains. TEM micrograph showed the spherical morphology of AgNPs with size range of $40-60 \mathrm{~nm}$. The synthesized nanoparticles showed a strong antimicrobial activity and their effect depends upon bacterial strain as AgNPs exhibited greater inhibition zone for Pseudomonas aeruginosa (19.1 mm) followed by Staphylococcus aureus (14.8 mm) and S. pyogenes $(13.6 \mathrm{~mm})$ while the least activity was observed for Salmonella typhi $(12.5 \mathrm{~mm})$ at concentration of $5 \mu \mathrm{g} / \mathrm{disc}$. The minimum inhibitory concentration (MIC) of AgNPs against S. aureus was $2.5 \mu \mathrm{g} / \mathrm{disc}$ and less than $2.5 \mu \mathrm{g} / \mathrm{disc}$ for $P$. aeruginosa. These results suggested that AgNPs can be used as an effective antiseptic agent for infectious control in medical field.

\section{Introduction}

Nanotechnology has been recognized as the most auspicious field of multidisciplinary science [1]. Owing to their small size, nanoparticles (NPs) embrace exceptional physicochemical properties, which are entirely dissimilar to their majority counterparts [2]. These physicochemical properties have been comprehensively exploited in numerous fields, including material science, aerospace engineering, biotechnology, and medical and dental field [3]. Among several NPs, silver (Ag) NPs have contributed enormously to the improvement of nanotechnology and have been the subject of extensive research over several decades [4]. Silver in the nanoscale form displays extraordinarily unusual biological and physicochemical activities and thus has been extensively applied in various fields including health care segment $[5,6]$. Precisely, the exceptional silver NPs antimicrobial properties have accomplished the improvement of a widespread diversity of nanosilver products, comprising nanosilver coated lesion bandages, contraceptive tools, surgical devices, and implants [7-9]. Certainly, the applications of silver in metallic form can be traced back to ancient times, and its primary medicinal application was described in the 8th century [10]. Nevertheless, due to the great attainments made in tuning the physicochemical properties of AgNPs and latest development in the synthesis and characterization of metallic NPs, AgNPs came to the forefront of nanotechnological investigation [1113].

Silver nanoparticles have drawn intensive interest in the recent years due to their low-cost, high efficiency, and unique optical and electronic properties which lead to potential applications in industrial fields. In the prolific literature of metal nanoparticles, silver nanoparticles have acquired a lot of attention due to the wide range of properties displayed by 
them in the area of catalysis, electronics, sensors, and surface enhanced Raman scattering (SERS) [14-17]. Other than these, medical field is one of the leading areas of research where AgNPs have been found to play an important role due to the strong bactericidal and inhibitory properties against broad spectrum of bacterial strains possessed by them. AgNPs are reported to possess antimicrobial [18], antifungal [19], antiviral [20], anti-inflammatory [21], antiplatelet [22], and antiangiogenesis activity [23].

Silver NPs have been synthesized by using several physical and chemical approaches based on the accessibility and feasibility of protocols to achieve the essential applications $[24,25]$. The physical methods, which are also classified as "top-down approach," for the preparation of AgNPs include ball milling, flame pyrolysis, electric arc discharge, and laser ablation [26, 27]. These methods often require expensive instruments, high temperature, and pressure [28], whereas the "bottom-up approach," which includes the chemical methods, involves the concepts of wet chemistry. In this process, the formation of NPs is carried out via the reduction/decomposition of metal complexes in solutions using various chemical reductants, such as sodium borohydride and hydrazine, at elevated temperatures [2931]. Though, controlled synthesis of AgNPs can be achieved in large scale using aforementioned chemical reductants. However, the use of these chemicals reductants during the synthesis of AgNPs has adverse effects on their biological applications, and they are also potentially hazardous to the environment [32]. Therefore, synthesis of AgNPs using relatively less hazardous and harmless chemical reducing agents is highly desirable. In this regard, several attempts have been made using various other reagents, such as ascorbic acid, sodium citrate, and glucose, which are considered to be mild and relatively less hazardous, when compared to the strong chemical reducing agents. Furthermore, to attain stable dispersions of AgNPs to make them compatible in various applications often requires various stabilizers to prevent aggregation [33, 34]. Among various chemical methods that applied mild reducing agents, the preparation of AgNPs by the reduction of silver salts with citrate ions has gained immense interest. Citrate ions undergo strong surface interaction with Ag nanocrystallites and facilitate slow crystal growth during the reduction process, which helps in the controlled synthesis of NPs. Therefore, citrate ions not only act as reducing agents but also function as excellent stabilizers [35].

So far, immense studies have been conducted focusing on the synthesis of AgNPs using citrate ion as reducing agents $[36,37]$. However, there is a lot to explore in the biological aspect of these nanoparticles with respect to the antibacterial and antifungal activity of the silver nanoparticles synthesized with these citrate ions. Hence, this paper focuses on the antimicrobial activity of the chemically synthesized silver nanoparticles using citrate ions as reducing and stabilizing agent. In the present study, the citrate mediated synthesized Ag nanoparticles were characterized by using various techniques, including UV/Vis, TEM, EDX, and XRD. The as synthesized silver NPs were evaluated for their antimicrobial activity against several bacterial strains. The results exhibited that AgNPs can be used as an effective antiseptic agent for infectious control in medical field.

\section{Materials and Methods}

2.1. Synthesis of Silver Nanoparticles (NPs). Ag nanoparticles were synthesized by previously reported method as follows [38]. Aqueous silver nitrate solution was used as a metal salt precursor while sodium citrate solution was applied as a stabilizing and reducing agent at elevated temperature. To begin with, $0.001 \mathrm{M}$ of $\mathrm{AgNO}_{3}$ (99\%, Sigma Aldrich, USA) was dissolved in $50 \mathrm{~mL}$ of water at boiling temperature. Subsequently, $5 \mathrm{~mL}$ of $1 \%$ trisodium citrate (99\%, Sigma Aldrich, USA) was added dropwise to this boiling solution. The colorless solution was allowed to stir at boiling temperature until the color of the solution is changed to greenish yellow. This clearly indicated the formation of silver nanoparticles. Therefore, the reaction was stopped and allowed to cool down at room temperature and the product was extracted by centrifugation. To eliminate surplus silver ions, the silver colloids were washed at least three times with deionized (DI) water and dried at $70^{\circ} \mathrm{C}$ for three successive days. A dried powder of the nanosized silver was obtained.

\subsection{Characterizations of NPs}

2.2.1. UV/Vis Spectroscopy. A Perkin Elmer lambda 35 (USA) UV-Vis spectrophotometer was employed to conduct optical measurements. The UV samples for the pure silver NPs were prepared by diluting $2 \mathrm{~mL}$ of stock solution of pure silver NPs in $8 \mathrm{~mL}$ of water. The stock solutions were prepared by dispersing $5 \mathrm{mg}$ of silver NPs in $5 \mathrm{~mL}$ of water by 1-hour sonication.

2.2.2. X-Ray Diffraction. XRD patterns were collected on an Altima IV [Rigaku, Japan] X-ray powder diffractometer using $\mathrm{Cu} \mathrm{K} \alpha$ radiation $(\lambda=1.5418 \AA)$.

2.2.3. Transmission Electron Microscopy. Transmission electron microscopy (TEM) was performed on a JEOL JEM 1101 (USA) transmission electron microscope. The dispersion for the TEM samples (primary solution) was prepared by taking $1 \mathrm{mg}$ of as synthesized AgNPs in $5 \mathrm{~mL}$ of ethanol, which was sonicated for $15 \mathrm{~min}$. The samples for TEM were prepared by placing a drop of primary solution on a commercially available copper grid, which were dried for 6 hours at $80^{\circ} \mathrm{C}$ in an oven.

\subsection{Antibacterial Activity of Silver Nanoparticle}

2.3.1. Bacterial Strains. The as synthesized sliver nanoparticles were subjected to antibacterial evaluation, against both Gram positive and Gram negative bacterial strains such as Staphylococcus aureus and Streptococcus pyogenes (Gram positive) and Salmonella typhi and Pseudomonas aeruginosa (Gram negative). The identity of the bacterial strains was confirmed morphologically and by employing biochemical techniques. The microorganisms were provided from 
the culture collection of Botany and Microbiology Department, King Saud University, Riyadh, KSA.

2.3.2. Inoculums Preparation. Bacterial inocula were prepared by subculturing microorganisms into tryptone soya agar (TSA) slants at $37^{\circ} \mathrm{C}$ for $18 \mathrm{hrs}$. The growth was harvested using $5 \mathrm{~mL}$ of sterile saline water, diluted, and their absorbances were adjusted at $580 \mu \mathrm{m}$ to $25 \%$ using spectrophotometer. The viable cell count at this absorbance was approximately $10^{7} \mathrm{CFU} / \mathrm{mL}$ of each bacterial strain.

2.3.3. Antibacterial Assay. Agar disk diffusion method is used to evaluate antimicrobial activity of the sensitized Ag nanoparticles. $10 \mathrm{~mL}$ of TSA medium was poured into sterile petri dishes (as a basal layer) followed by $15 \mathrm{~mL}$ of seeded medium previously inoculated with bacterial suspension $\left(100 \mathrm{~mL}\right.$ of medium $/ 1 \mathrm{~mL}$ of $\left.10^{7} \mathrm{CFU}\right)$ to attain $10^{5} \mathrm{CFU} / \mathrm{mL}$ of medium. Sterile filter paper discs (6 $\mathrm{mm}$ in diameter) were loaded with $5 \mu \mathrm{g}$ of $\mathrm{Ag}$ nanoparticles solutions and placed on the top of the TSA plates. Filter paper discs loaded with $5 \mu \mathrm{g}$ of Gentamycin were used as positive control. The plates were incubated at $37^{\circ} \mathrm{C}$ for $24 \mathrm{hrs}$ and the presence of inhibition zones was recorded, measured by Vernier caliper, and considered as indication

2.3.4. Determination of Minimum Inhibitory Concentration (MIC) of AgNPs. MIC is defined as the lowest concentration of the antimicrobial agent that inhibits the growth of microorganism after $24 \mathrm{hrs}$ of incubation. AgNP was manipulated to determine its minimal inhibitory concentration (MIC) to evaluate its efficiency in controlling pathogenic bacteria $(S$. aureus and $P$. aeruginosa).

Different concentrations of AgNPs (2.5, 5.0, 10.0, 15.0, 20.0 , and $25.0 \mu \mathrm{g} / \mathrm{mL}$ ) were prepared separately by dissolving their requisite amount in $5 \mathrm{~mL}$ of ethanol, sterilized, and loaded over sterilized filter paper discs (6 $\mathrm{mm}$ in diameter). Ten $\mathrm{mL}$ of TSA basal medium followed by $15 \mathrm{~mL}$ of TSA seeded medium (previously inoculated with bacterial suspensions of pathogenic bacteria (S. aureus and P. aeruginosa)) was poured into sterile petri dishes. Filter paper discs loaded with different concentrations of AgNPs were placed on the top of the TSA plates. The plates were incubated at $37^{\circ} \mathrm{C}$ for $24 \mathrm{hrs}$ and the presence of inhibition zones was measured by Vernier caliper and recorded against the concentrations of AgNPs.

\section{Results and Discussion}

3.1. UV-Vis Spectral Analysis. UV/Vis absorption spectroscopy is a vital analytical system to monitor the formation and consistency of metal NPs in aqueous solution. The UV/Vis absorption spectrum (Figure 1) obtained from the analysis of metal NPs is susceptible to various factors such as particle size, shape, and agglomeration (particle-particle interaction) with the medium [3]. Therefore, the aqueous bioreduction of $\mathrm{Ag}^{+}$ions can be effectively monitored by UV/Vis spectrophotometer. The spectral response of silver nanoparticles is based on the diameter of the nanoparticle. The peak broadens and there is a Plasmon resonance shift

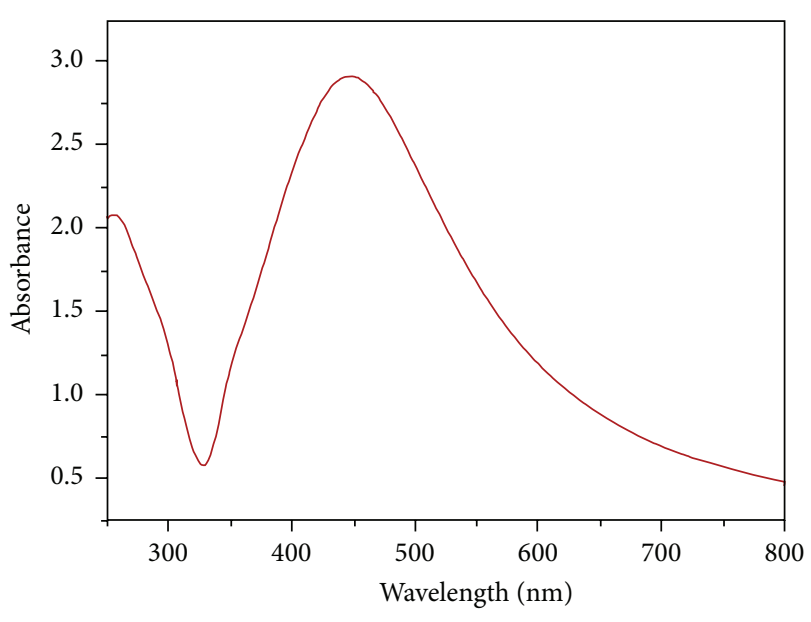

Figure 1: UV-Vis absorption spectra of AgNPs.

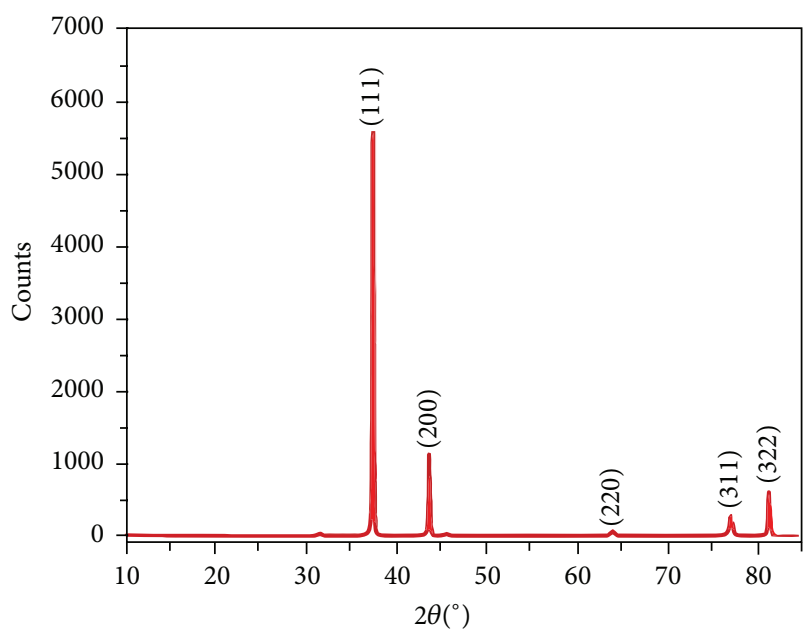

Figure 2: XRD pattern of the synthesized AgNPs.

towards longer wavelengths, as the diameter increases. The $\lambda_{\max }$ value obtained indicates the size of $40-50 \mathrm{~nm}$ which is corroborated by TEM.

3.2. Powder X-Ray Diffraction. The crystalline nature of the synthesized AgNPs has been confirmed by the analysis of the X-ray diffraction (XRD) pattern. The XRD pattern in Figure 2 indicates the face-centered cubic (FCC) structure of the AgNPs. There are five discrete reflections in the diffractogram at $37.5^{\circ}(111), 44.1^{\circ}(200), 63.9^{\circ}(220), 76.8^{\circ}$ (311), and $81.1^{\circ}(222)$. The intense reflection at (111) compared to the other four possibly indicates the growth direction of the nanocrystals.

The average grain size $L$ was calculated using the DebyeScherer formula $(D=K \lambda /(\beta \cos \theta))$ employing the halfwidth $(\Lambda)$ of the (111) reflection in the powder pattern, which yielded that the average grain size $L$ is approximately $42 \mathrm{~nm}$.

3.3. TEM and EDX Analysis. The shape and size of the prepared AgNPs were examined employing TEM. The TEM 

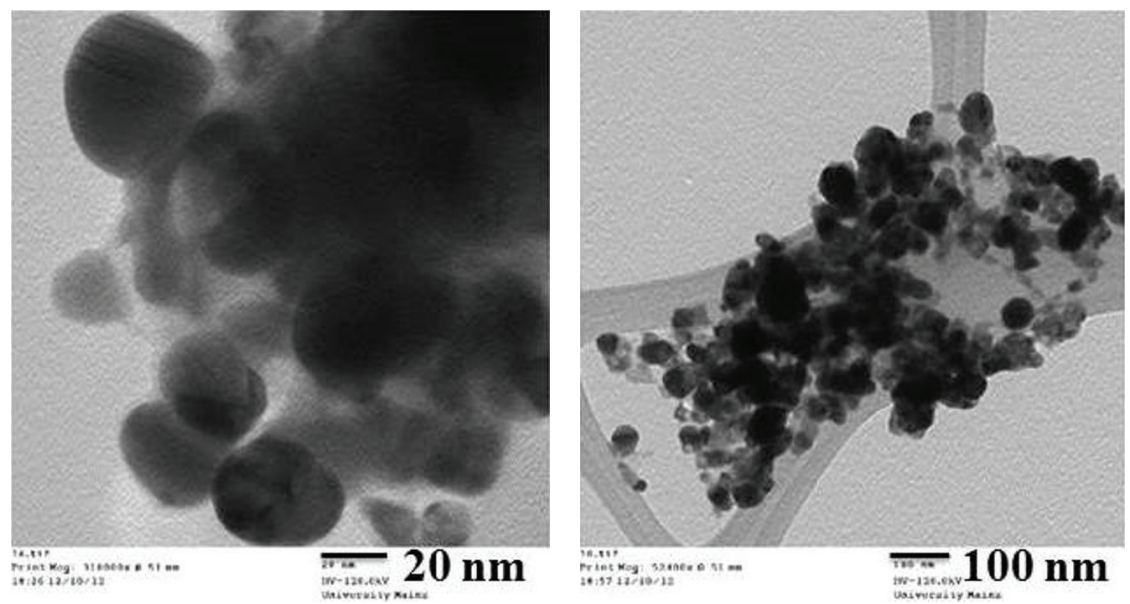

Figure 3: TEM images of the synthesized AgNPs.

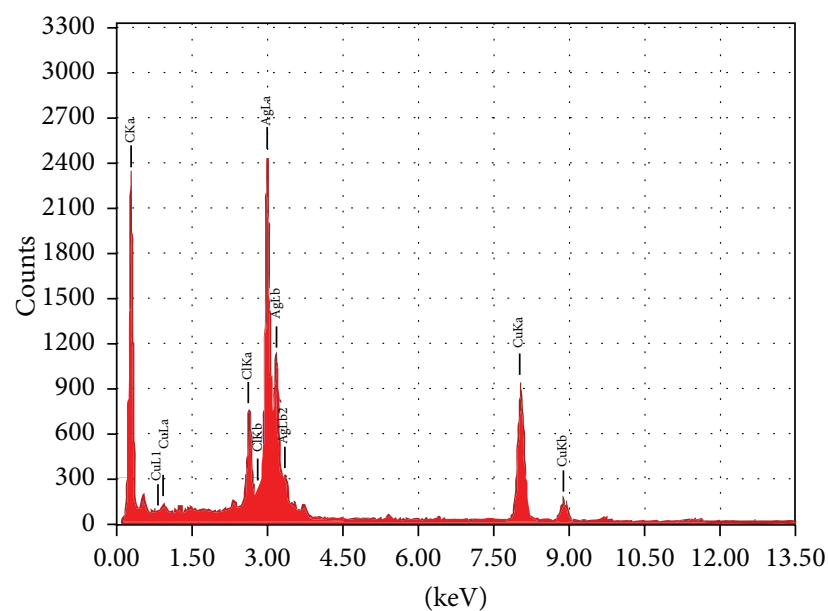

FIgURE 4: Energy dispersive X-ray spectrum of the synthesized AgNPs.

images (Figure 3) show overview image of the as synthesized NPs and show the spherical morphology of NPs, within a size range of $42-58 \mathrm{~nm}$, in which few NPs were agglomerated. Furthermore, the elemental composition of the synthesized sample was also determined by energy dispersive $\mathrm{X}$-ray analysis. The EDX spectral analysis revealed that Ag is the major element in the obtained product, which was concluded by the presence of intense signal at $3 \mathrm{keV}$, which is due to an optical absorption in this range due to the surface Plasmon resonance [3]. The EDX spectrum is given in Figure 4.

3.4. Antibacterial Assay of AgNPs. The antibacterial assay of Ag nanoparticles was screened because of the great medicinal relevance of AgNPs and their numerous applications [39]. Antibacterial activity of AgNPs was preformed against the Gram positive pathogenic bacteria S. aureus and S. pyogenes and two strains of Gram negative pathogenic bacteria ( $S$. typhi and $P$. aeruginosa) using agar disc diffusion method at concentration of $5 \mu \mathrm{g} /$ disc. Evaluations of their antibacterial activities were recorded in Table 1.

The result revealed that AgNPs exhibited a potential antibacterial activity against all the tested bacterial strains and their activity was varied with bacterial strain at the same concentration. The Ag nanoparticles exhibited greater inhibition zone for $P$. aeruginosa $(19.1 \mathrm{~mm})$ followed by $S$. aureus $(14.8 \mathrm{~mm})$ and $S$. pyogenes $(13.6 \mathrm{~mm})$ while the least activity was observed for $S$. typhi $(12.5 \mathrm{~mm})$ at $5 \mu \mathrm{g} / \mathrm{disc}$.

3.5. Minimum Inhibitory Concentration (MIC) of AgNPs. The minimum inhibitory concentration was evaluated to determine the lowest concentration of AgNPs that completely inhibited the visible bacterial growth. The MIC of AgNPs against Gram (+ve) S. aureus and Gram (-ve) P. aeruginosa are shown in Table 2 and illustrated in Figure 5. The results showed that the MIC of AgNPs against S. aureus was $2.5 \mu \mathrm{g} / \mathrm{mL}$ while MIC of AgNPs against P. aeruginosa will be less than $2.5 \mu \mathrm{g} / \mathrm{mL}$. Thus we can conclude from the result of this study that the AgNPs inhibited growth of the tested microorganisms and $P$. aeruginosa is highly susceptible to AgNPs concentrations compared to that of $S$. aureus.

Several studies were carried out to demonstrate the antimicrobial activity of AgNPs. Lkhagvajav et al. [40], showed that AgNPs synthesized by sol-gel method were effective against $S$. aureus, E. coli, and $P$. aeruginosa at $2-4 \mu \mathrm{g} / \mathrm{mL}$, while Shameli et al. [41], recorded that AgNPs (mean size $11 \mathrm{~nm}$ ) prepared by green synthesis method were effective against $S$. aureus and Salmonella typhi at concentration of $20 \mu \mathrm{L}$ of AgNPs. Also, Zarei et al. [42], investigated the antimicrobial activity of silver nanoparticles and they found that MIC of AgNPs against E. coli, Listeria monocytogenes, Salmonella typhimurium, and Vibrio parahaemolyticus were in the range of $3.12-6.25 \mu \mathrm{g} / \mathrm{mL}$. In contrast, Gopinath et al. [43], reported that AgNPs (mean particle size ranged from 20 to $50 \mathrm{~nm}$ ) synthesized by green method using Pterocarpus santalinus leaf extract were an effective bactericide against $S$. aureus, Streptococcus pneumoniae, $P$. aeruginosa, and Shigella dysenteriae at a higher concentration that reached $100 \mu \mathrm{L}$ of 

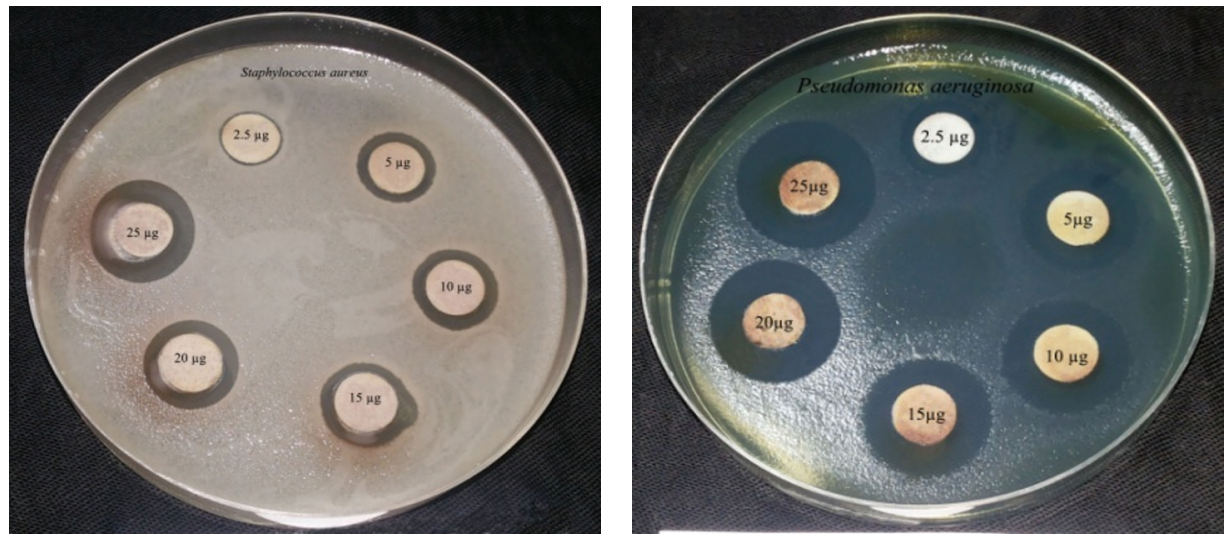

Figure 5: Minimum inhibitory concentration (MIC) of AgNPs against S. aureus and P. aeruginosa.

TABLE 1: Antibacterial activity of AgNPs against some Gram (+ve) and Gram (-ve) pathogenic bacteria.

\begin{tabular}{lcccc}
\hline \multirow{2}{*}{ Conc. of AgNPs $(\mu \mathrm{g} / \mathrm{disc})$} & \multicolumn{3}{c}{ Inhibition zones $(\mathrm{mm})$} \\
& \multicolumn{2}{c}{ Gram $(+\mathrm{ve})$ pathogenic bacteria } & \multicolumn{2}{c}{ Gram (-ve) pathogenic bacteria } \\
\hline $\mathrm{Ag}(5 \mu \mathrm{g} / \mathrm{disc})$ & S. aureus & S. pyogenes & S. typhi & P. aeruginosa \\
$(+\mathrm{ve})$ control & $14.8 \pm 0.4$ & $13.6 \pm 0.1$ & $12.5 \pm 0.3$ & $19.1 \pm 0.2$ \\
\hline
\end{tabular}

Data are means of three replicates ( $n=3 \pm$ standard error)

TABle 2: Minimum inhibitory concentration of AgNPs against S. aureus and P. aeruginosa.

\begin{tabular}{lcc}
\hline Conc. of Ag nanoparticle $(\mu \mathrm{g} /$ disc $)$ & \multicolumn{2}{c}{$\begin{array}{c}\text { Inhibition zones }(\mathrm{mm}) \\
\text { Gram }(-\mathrm{ve}) \text { pathogenic bacteria } \\
\text { P. aeruginosa }\end{array}$} \\
\hline 2.5 & S. aureus $(+\mathrm{ve})$ pathogenic bacteria & $12.5 \pm 0.3$ \\
5.0 & $11.0 \pm 0.2$ & $16.5 \pm 1.0$ \\
10 & $12.5 \pm 0.4$ & $18.5 \pm 0.2$ \\
15 & $14.0 \pm 0.5$ & $20.8 \pm 0.4$ \\
20 & $15.3 \pm 0.7$ & $22.5 \pm 0.3$ \\
25 & $16.0 \pm 0.3$ & $24.5 \pm 0.7$ \\
\hline
\end{tabular}

Data are means of three replicates ( $n=3 \pm$ standard error).

AgNPs. Our results showed that the MIC of AgNPs against Gram (+ve) S. aureus and Gram (-ve) P. aeruginosa were $2.5 \mu \mathrm{g} / \mathrm{mL}$ and less than $2.5 \mu \mathrm{g} / \mathrm{mL}$, respectively. These results were coincident with that reported by Lkhagvajav et al. [40].

\section{Conclusions}

It is well reported in literature that bacteria have different cell wall structure and their ability of capsule formation, due to which their susceptibility towards antibacterial agents differs. Reports suggested that antimicrobial activity of silver nanoparticle is associated with the structure of bacterial cell wall and thickness of peptidoglycan layer of bacterial cell wall, while there are several other reports that attributed the inhibitory effect of silver nanoparticles to their particle size which enables them to easily get attached to bacterial cell membrane and reach nuclear content of the bacterial cell, resulting in a disturbance in their structure and rendering them permeable to a larger extent, that leads to the leaking of ions and other cell contents. This kind of disturbance in the enzymatic activity inside the bacterial cell results in the death of the bacterial cell. Chemically synthesized silver nanoparticles were evaluated for their antimicrobial activity against various Gram (+ve) and Gram (-ve) bacterial strains such as $S$. aureus, S. pyogenes and S. typhi, and P. aeruginosa, respectively. The zone of inhibition was recorded to evaluate the antimicrobial activity and the MIC values were calculated. The results obtained displayed great variation in the antimicrobial activity of AgNPs wherein the synthesized AgNPs were found to be strongly active against Gram (+ve) bacterial strain $S$. aureus and Gram (-ve) bacterial strain P. aeruginosa; the MIC value was found to be $2.5 \mu \mathrm{g} / \mathrm{mL}$ and less than $2.5 \mu \mathrm{g} / \mathrm{mL}$, respectively, while displaying moderate activity against $S$. typhi especially at concentration of $5 \mu \mathrm{g} / \mathrm{mL}$. These results suggested that antimicrobial activity of silver nanoparticle 
may be associated with characteristics of certain bacterial species, which needs further studies in order to ascertain the mode of action due to which the as synthesized nanoparticles display antibacterial activity. Studies are also underway to find out how surface modification of AgNPs can affect the antimicrobial activity, which shall be reported later.

\section{Conflict of Interests}

The authors declare that there is no conflict of interests regarding the publication of this paper.

\section{Acknowledgment}

This project was supported by King Saud University, Deanship of Scientific Research, College of Science, Research Center.

\section{References}

[1] S. K. Sahoo, S. Parveen, and J. J. Panda, "The present and future of nanotechnology in human health care," Nanomedicine: Nanotechnology, Biology, and Medicine, vol. 3, no. 1, pp. 20-31, 2007.

[2] S. K. Nune, N. Chanda, R. Shukla et al., "Green nanotechnology from tea: phytochemicals in tea as building blocks for production of biocompatible gold nanoparticles," Journal of Materials Chemistry, vol. 19, no. 19, pp. 2912-2920, 2009.

[3] C. N. R. Rao, H. S. S. R. Matte, R. Voggu, and A. Govindaraj, "Recent progress in the synthesis of inorganic nanoparticles," Dalton Transactions, vol. 41, no. 17, pp. 5089-5120, 2012.

[4] C. N. R. Rao, S. R. C. Vivekchand, K. Biswas, and A. Govindaraj, "Synthesis of inorganic nanomaterials," Dalton Transactions, no. 34, pp. 3728-3749, 2007.

[5] Y. Barnea, J. Weiss, and E. Gur, "A review of the applications of the hydrofiber dressing with silver (Aquacel Ag) in wound care," Therapeutics and Clinical Risk Management, vol. 6, no. 1, pp. 2127, 2010.

[6] C. Wen, A. Yin, and W.-L. Dai, "Recent advances in silver-based heterogeneous catalysts for green chemistry processes," Applied Catalysis B: Environmental, vol. 160-161, no. 1, pp. 730-741, 2014.

[7] C. A. Dos Santos, M. M. Seckler, A. P. Ingle et al., "Silver nanoparticles: therapeutical uses, toxicity, and safety issues," Journal of Pharmaceutical Sciences, vol. 103, no. 7, pp. 1931-1944, 2014.

[8] C. W. Li, R. Q. Fu, C. P. Yu et al., "Silver nanoparticle/chitosan oligosaccharide/poly(vinyl alcohol) nanofibers as wound dressings: a preclinical study," International Journal of Nanomedicine, vol. 8, pp. 4131-4145, 2013.

[9] A. M. Fayaz, Z. Ao, M. Girilal et al., "Inactivation of microbial infectiousness by silver nanoparticles-coated condom: a new approach to inhibit HIV- and HSV-transmitted infection," International Journal of Nanomedicine, vol. 7, pp. 5007-5018, 2012.

[10] C. A. Moyer, "A treatment of burns," Transactions \& Studies of the College of Physicians of Philadelphia, vol. 33, no. 2, pp. 53$103,1965$.

[11] S. Nie and S. R. Emory, "Probing single molecules and single nanoparticles by surface-enhanced Raman scattering," Science, vol. 275, no. 5303, pp. 1102-1106, 1997.
[12] J. Nelayah, M. Kociak, O. Stéphan et al., "Mapping surface plasmons on a single metallic nanoparticle," Nature Physics, vol. 3, no. 5, pp. 348-353, 2007.

[13] M. Grzelczak and L. M. Liz-Marzán, “The relevance of light in the formation of colloidal metal nanoparticles," Chemical Society Reviews, vol. 43, no. 7, pp. 2089-2097, 2014.

[14] S. F. Adil, M. E. Assal, M. Khan, A. Al-Warthan, and M. H. Rafiq Siddiqui, "Nano silver-doped manganese oxide as catalyst for oxidation of benzyl alcohol and its derivatives: synthesis, characterisation, thermal study and evaluation of catalytic properties," Oxidation Communications, vol. 36, no. 3, pp. 778-791, 2013.

[15] M. R. H. Siddiqui, S. F. Adil, K. Nour, M. E. Assal, and A. AlWarthan, "Ionic liquid behavior and high thermal stability of silver chloride nanoparticles: synthesis and characterization," Arabian Journal of Chemistry, vol. 6, no. 4, pp. 435-438, 2013.

[16] A. H. Alshehri, M. Jakubowska, A. Młoziniak et al., "Enhanced electrical conductivity of silver nanoparticles for high frequency electronic applications," ACS Applied Materials and Interfaces, vol. 4, no. 12, pp. 7007-7010, 2012.

[17] S. Gómez-Graña, J. Pérez-Juste, R. A. Alvarez-Puebla, A. Guerrero-Martínez, and L. M. Liz-Marzán, "Self-assembly of $\mathrm{Au} @ \mathrm{Ag}$ nanorods mediated by gemini surfactants for highly efficient SERS-active supercrystals," Advanced Optical Materials, vol. 1, no. 7, pp. 477-481, 2013.

[18] M. Rai, A. Yadav, and A. Gade, "Silver nanoparticles as a new generation of antimicrobials," Biotechnology Advances, vol. 27, no. 1, pp. 76-83, 2009.

[19] L. Esteban-Tejeda, F. Malpartida, C. Pecharromán, and J. S. Moya, "High antibacterial and antifungal activity of silver monodispersed nanoparticles embedded in a glassy matrix," Advanced Engineering Materials, vol. 12, no. 7, pp. B292-B297, 2010.

[20] L. Lu, R. W.-Y. Sun, R. Chen et al., "Silver nanoparticles inhibit hepatitis B virus replication," Antiviral Therapy, vol. 13, no. 2, pp. 252-262, 2008.

[21] K. K. Y. Wong, S. O. F. Cheung, L. Huang et al., "Further evidence of the anti-inflammatory effects of silver nanoparticles," ChemMedChem, vol. 4, no. 7, pp. 1129-1135, 2009.

[22] R. N. Krishnaraj and S. Berchmans, "In vitro antiplatelet activity of silver nanoparticles synthesized using the microorganism Gluconobacter roseus: an AFM-Based Study," RSC Advances, vol. 3, no. 23, pp. 8953-8959, 2013.

[23] J. Baharara, F. Namvar, M. Mousavi, T. Ramezani, and R. Mohamad, "Anti-angiogenesis effect of biogenic silver nanoparticles synthesized using Saliva officinalis on chick chorioalantoic membrane (CAM)," Molecules, vol. 19, no. 9, pp. 13498-13508, 2014.

[24] Y. Sun, "Controlled synthesis of colloidal silver nanoparticles in organic solutions: empirical rules for nucleation engineering," Chemical Society Reviews, vol. 42, no. 7, pp. 2497-2511, 2013.

[25] A. K. Samal, L. Polavarapu, S. Rodal-Cedeira, L. M. LizMarzán, J. Pérez-Juste, and I. Pastoriza-Santos, "Size tunable Au@Ag core-shell nanoparticles: synthesis and surfaceenhanced raman scattering properties," Langmuir, vol. 29, no. 48, pp. 15076-15082, 2013.

[26] S. L. James, C. J. Adams, C. Bolm et al., "Mechanochemistry: opportunities for new and cleaner synthesis," Chemical Society Reviews, vol. 41, no. 1, pp. 413-447, 2012.

[27] Y. Hu, Y. Shi, H. Jiang, G. Huang, and C. Li, "Scalable preparation of ultrathin silica-coated Ag nanoparticles for SERS 
application," ACS Applied Materials \& Interfaces, vol. 5, no. 21, pp. 10643-10649, 2013.

[28] H. Xu, B. W. Zeiger, and K. S. Suslick, "Sonochemical synthesis of nanomaterials," Chemical Society Reviews, vol. 42, no. 7, pp. 2555-2567, 2013.

[29] M. N. Tahir, F. Natalio, M. A. Cambaz et al., "Controlled synthesis of linear and branched Au@ZnO hybrid nanocrystals and their photocatalytic properties," Nanoscale, vol. 5, no. 20, pp. 9944-9949, 2013.

[30] L. Polavarapu and L. M. Liz-Marzán, "Growth and galvanic replacement of silver nanocubes in organic media," Nanoscale, vol. 5, no. 10, pp. 4355-4361, 2013.

[31] K. S. Tan and K. Y. Cheong, "Advances of $\mathrm{Ag}, \mathrm{Cu}$, and $\mathrm{Ag}-\mathrm{Cu}$ alloy nanoparticles synthesized via chemical reduction route," Journal of Nanoparticle Research, vol. 15, no. 4, article 1537, 2013.

[32] H. Duan, D. Wang, and Y. Li, "Green chemistry for nanoparticle synthesis," Chemical Society Reviews, vol. 44, no. 16, pp. 57785792, 2015.

[33] S. Mourdikoudis and L. M. Liz-Marzán, "Oleylamine in nanoparticle synthesis," Chemistry of Materials, vol. 25, no. 9, pp. 1465-1476, 2013.

[34] V. Montes-García, J. Pérez-Juste, I. Pastoriza-Santos, and L. M. Liz-Marzán, "Metal nanoparticles and supramolecular macrocycles: a tale of synergy," Chemistry-A European Journal, vol. 20, no. 35, pp. 10874-10883, 2014.

[35] Z. S. Pillai and P. V. Kamat, "What factors control the size and shape of silver nanoparticles in the citrate ion reduction method?" The Journal of Physical Chemistry B, vol. 108, no. 3, pp. 945-951, 2004.

[36] S. Wojtysiak and A. Kudelski, "Influence of oxygen on the process of formation of silver nanoparticles during citrate/borohydride synthesis of silver sols," Colloids and Surfaces A: Physicochemical and Engineering Aspects, vol. 410, pp. 45-51, 2012.

[37] M. Baalousha, Y. Nur, I. Römer, M. Tejamaya, and J. R. Lead, "Effect of monovalent and divalent cations, anions and fulvic acid on aggregation of citrate-coated silver nanoparticles," Science of the Total Environment, vol. 454-455, pp. 119-131, 2013.

[38] P. Van Dong, C. H. Ha, and J. Kasbohm, "Chemical synthesis and antibacterial activity of novel-shaped silver nanoparticles," International Nano Letters, vol. 2, no. 1, pp. 1-9, 2012.

[39] C. Dipankar and S. Murugan, "The green synthesis, characterization and evaluation of the biological activities of silver nanoparticles synthesized from Iresine herbstii leaf aqueous extracts," Colloids and Surfaces B: Biointerfaces, vol. 98, pp. 112119, 2012.

[40] N. Lkhagvajav, I. Yaşa, E. Çelik, M. Koizhaiganova, and O. Sari, "Antimicrobial activity of colloidal silver nanoparticles prepared by sol-gel method," Digest Journal of Nanomaterials and Biostructures, vol. 6, no. 1, pp. 149-154, 2011.

[41] K. Shameli, M. B. Ahmad, S. D. Jazayeri et al., "Investigation of antibacterial properties silver nanoparticles prepared via green method," Chemistry Central Journal, vol. 6, no. 1, article 73, 2012.

[42] M. Zarei, A. Jamnejad, and E. Khajehali, "Antibacterial effect of silver nanoparticles against four foodborne pathogens," Jundishapur Journal of Microbiology, vol. 7, no. 1, article e8720, 2014.

[43] V. Gopinath, S. Priyadarshini, N. M. Priyadharsshini, K. Pandian, and P. Velusamy, "Biogenic synthesis of antibacterial silver chloride nanoparticles using leaf extracts of Cissus quadrangularis Linn," Materials Letters, vol. 91, pp. 224-227, 2013. 

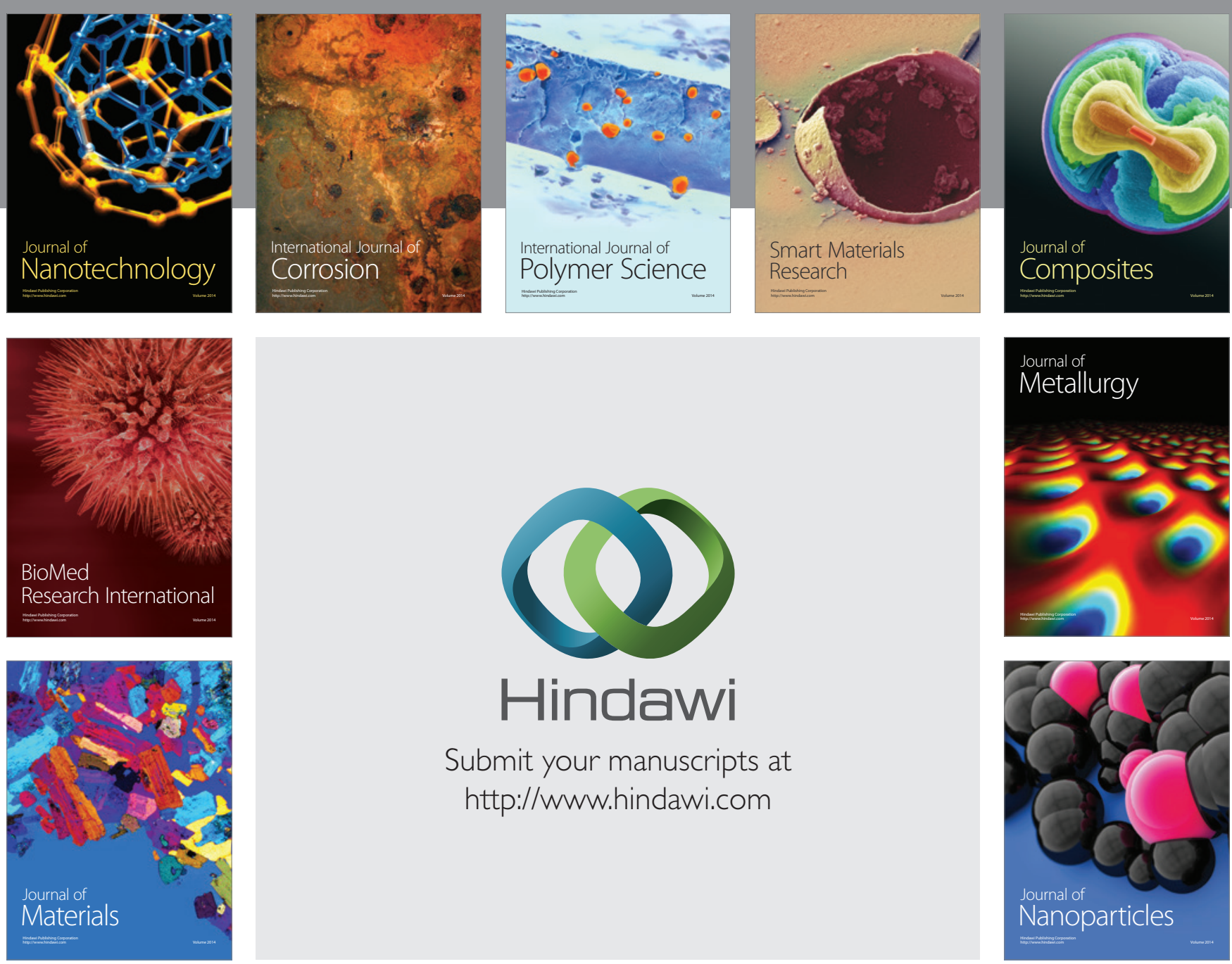

Submit your manuscripts at http://www.hindawi.com
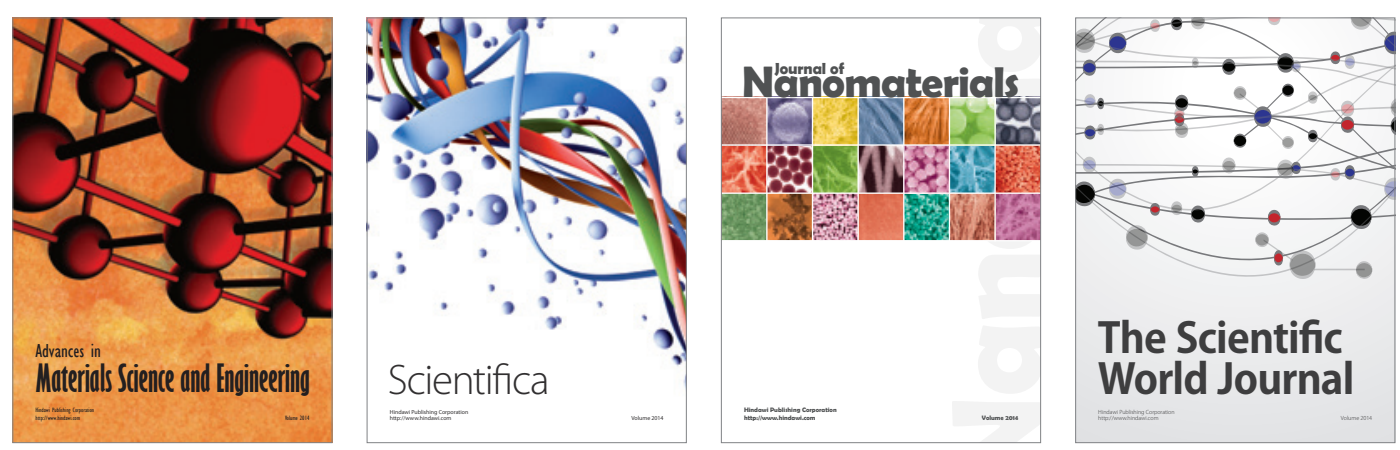

\section{The Scientific World Journal}
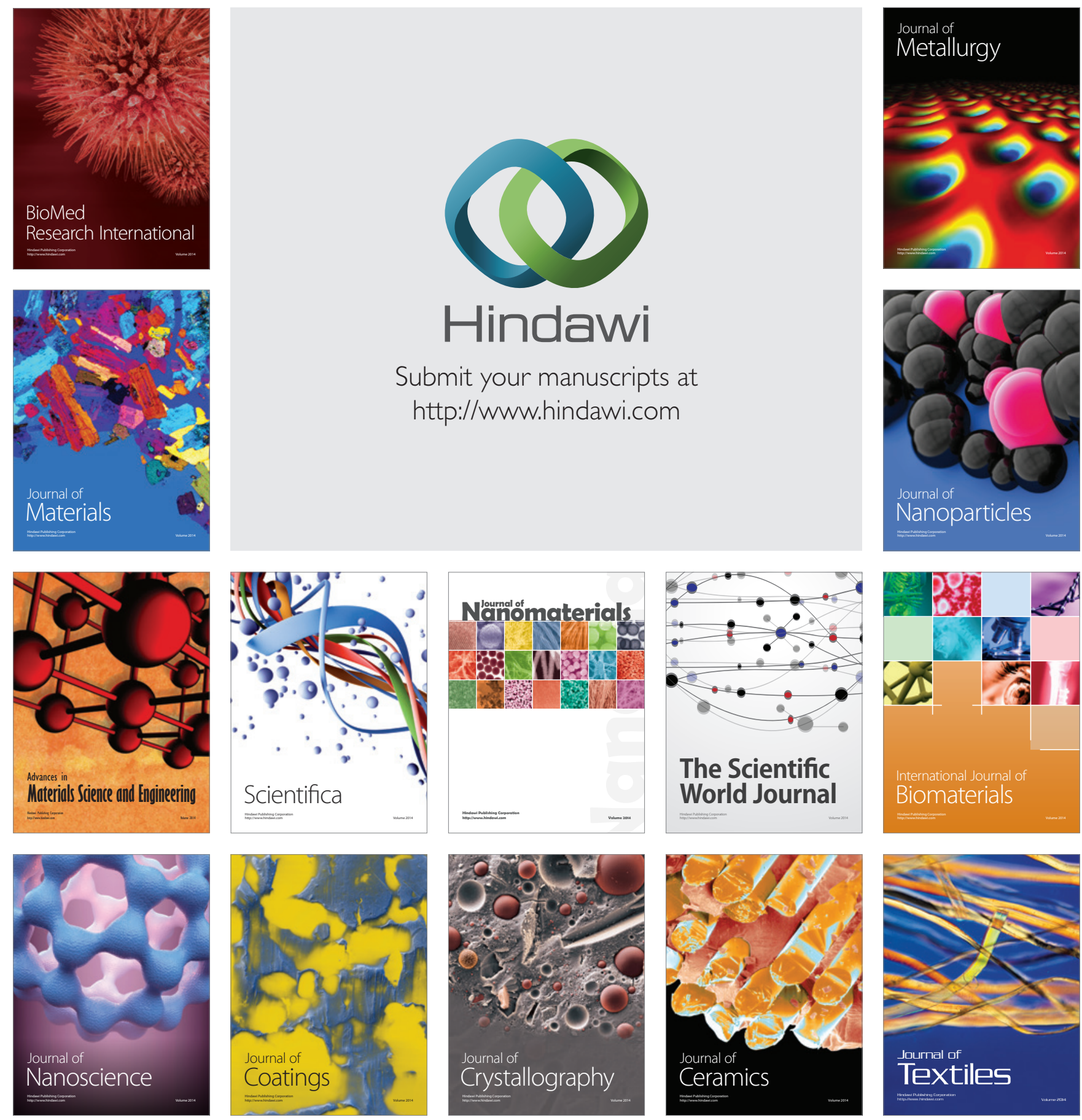